\title{
Going Back to Basics: Importance of Ecophysiology when Choosing Functional Traits for Studying Communities and Ecosystems
}

\author{
Bruno H. P. Rosado ${ }^{1 *}$, André T. C. Dias ${ }^{2}$ \& Eduardo A. de Mattos ${ }^{3}$
}

\author{
${ }^{1}$ Departamento de Ecologia, Instituto de Biologia Roberto Alcantara Gomes, \\ Universidade do Estado do Rio de Janeiro - UERJ, Rio de Janeiro, RJ, Brasil \\ ${ }^{2}$ Department of Ecological Science, Faculty of Earth and Life Sciences, VU University Amsterdam, \\ Amsterdam, The Netherlands \\ ${ }^{3}$ Departamento de Ecologia, Centro de Ciências da Saúde - CCS, Instituto de Biologia, \\ Universidade Federal do Rio de Janeiro - UFRJ, Rio de Janeiro, RJ, Brasil
}

\begin{abstract}
Striking progress has been made on conceptual and methodological aspects linking species traits to community and ecosystem responses to environmental change. However, the first step when using a trait-based approach (i.e., choosing the adequate traits reflecting species response to a given environmental driver) deserves much more attention. The first broad comparative studies, using worldwide datasets, have identified a number of traits that are, for example, good indicators of plant responses to water and nutrient availability, or good indicators of plant species defense against herbivory and plant effects on litter decomposition. Due to the successful explanation of global patterns of trait variation and the relatively easy measurements, some functional traits have become widely used. However, it is starting to be questioned whether the status of such "fashionable traits" is always justified; especially considering that particular traits might be the result of underlying traits that respond to distinct environmental factors. Some global trade-offs between traits reflecting contrasting resource use strategies do not hold under changing environmental conditions. Therefore, the choice of traits to up-scale responses of individuals to communities and ecosystems should be based on their adequacy for a specified ecological context. Here, we present a framework that helps identifying objective criteria for the choice of functional traits for studies on community assembly and ecosystem processes and services. This framework comprises five steps: 1) identification of the main environmental drivers; 2) identification of the relevant physiological processes allowing species to cope with the environment; 3) selection of traits that are involved in such physiological processes; 4) validation of the select traits at community level and; 5) evaluation of possible consequences for ecosystem processes/services.
\end{abstract}

Key words: Functional Diversity, Community Assembly, Ecosystem Functioning, Ecosystem Services, CWM.

\section{Introduction}

In the last decades, ecological literature has been strongly influenced by studies using species functional traits aiming for a more general understanding of community and ecosystem responses to environmental changes (Shipley et al. 2006; Suding et al. 2008). This approach gains importance in the current scenario of rapid degradation of natural systems due to global changes, as conservation biologists increasingly face the need to provide decision makers and stakeholders with data on causal mechanisms underlying conservation problems (Wikelski \& Cooke 2006). In this sense, functional traits have been used to assess, for instance,

\footnotetext{
${ }^{*}$ Send correspondence to: Bruno Rosado Departamento de Ecologia, Instituto de Biologia Roberto Alcantara Gomes, Universidade do Estado do Rio de Janeiro - UERJ, CEP 20550-013, Rio de Janeiro, RJ, Brasil E-mail: brunorosado@gmail.com
}

alterations in ecosystem services delivery due to human activity (de Bello et al. 2010), response of communities to climate changes (Fauset et al. 2012) and the performance of exotic invasive species (Drenovsky et al. 2012).

Striking progress has been made on conceptual (Lavorel \& Garnier 2002; Webb et al. 2010) and methodological (Cornelissen et al. 2003; Villéger et al. 2008; Dias et al. 2013a) aspects linking species traits to community and ecosystem responses. However, the first step for using a trait-based approach deserves much more attention. That is the criteria when choosing the adequate traits reflecting species response to a given environmental driver (Weiher et al. 1999; Díaz et al. 2002). The first broad comparative studies, using worldwide datasets, have identified a number of traits that are, for example, good indicators of plant responses to water and 
nutrient availability (Reich et al. 1992; Wright et al. 2004; Chave et al. 2009), or good indicators of plant species defense against herbivory and plant effects on litter decomposition (Cornelissen et al. 1999). Due to the successful explanation of global patterns of trait variation and the relatively easy measurements, some functional traits have become widely used. However, it is starting to be questioned whether the status of such "fashionable traits" is always justified (Díaz et al. 2002; Rosado \& de Mattos 2010; Wright \& Sutton-Grier 2012). Is the biological meaning of a given trait the same under different ecological contexts, spatial and temporal scales or in different regions of the globe? Apparently, the answer is "no" (Witkowski \& Lamont 1991; Rosado \& de Mattos 2010; Wright \& Sutton-Grier 2012). Some global trade-offs between traits reflecting contrasting resource use strategies (Wright et al. 2004) do not hold among environments subjected to varying conditions (Rosado \& de Mattos 2010; Wright \& Sutton-Grier 2012). Therefore, the choice of traits to up-scale responses of individuals to communities and ecosystems should be based on their adequacy under a specified ecological context.

Here, we argue that a better conceptual integration of ecophysiology within functional ecology is necessary for choosing the set of ecophysiological traits that adequately predict responses of communities and ecosystems to environmental changes. This should include a better understanding of the relation between functional traits and performance of organisms (Kraft et al. 2010). As we will show, selecting traits based on large comparative studies, regardless their effective functional significance in a local species pool, may lead to poor predictive power of ecological studies.

The reason behind this is that some "fashionable traits" are the product of other underlying traits, which may respond to different environmental factors (Witkowski \& Lamont 1991; Niinemets 2001; Zanne et al. 2010; Hodgson et al. 2011). We use as examples two widely used plant functional traits, leaf mass per area (LMA) and wood density (WD), which were repeatedly shown to be related to both species response to environmental conditions and to species effects on ecosystem functioning. Following Lavorel et al. (2008), who called attention to caveats when estimating functional diversity and interpreting results, our intention is to contribute with discussion of the criteria for choosing functional traits when studying community assembly and ecosystem processes/services. Here, we present a framework comprising five steps, which help in identifying objective criteria for the choice of functional traits. These steps are, in short, i) the identification of the main environmental drivers (e.g. climate changes, resource availability, disturbances) and ii) the relevant physiological processes allowing species to cope with them, iii) the selection of traits that are involved in such physiological processes and iv) the validation of the selected traits at the community and v) ecosystem scales.

\section{What Is Ecophysiology?}

For establishing the criteria for choosing traits, we advocate that the starting point should be the solid knowledge of species ecophysiology. Ecophysiology seeks to understand how species cope with variations in conditions and resources and how the responses of organisms affect their patterns of distribution and abundance, community structure and ecosystem processes (Beyschlag \& Ryel 2007; Lambers et al. 2008). A definition of plant ecophysiology illustrate this point:

[...] address ecological questions about the controls over growth, reproduction, survival, abundance and geographical distributions of plants as these processes are affected by the interactions between plants with their physical, chemical and biotic environment." (Lambers et al. 2008, p. 1).

This definition of ecophysiology is highly related to the aims of functional ecology and shows how important it is to strengthen the bridge between both disciplines.

Ecophysiological knowledge is fundamental for functional ecology and whenever morpho-physiological traits are chosen, it is necessary to understand their significance for ecological processes. For instance, ecophysiological approaches, even when not labeled as functional ecology, have been successfully used in studies on species distribution (Borchert 1994), functional convergence (Grime 1977; Wright et al. 2002), species interactions (Wardle et al. 1998), mechanism of coexistence (Markesteijn et al. 2011), environmental filtering (Grime 1977; Borchert 1994), ecosystem processes/services (Wardle et al. 1998) and conservation biology (Wikelski \& Cooke 2006).

\section{Can we Afford Fashion in the Choice of Traits?}

Global changes pose the urgent need to understand and predict changes in biological communities and its possible consequences to ecosystem functioning. The use of the trait-based approach has successfully simplified the multitude of species to few key traits that can be used as proxies for species response to environmental changes. Large scale comparative studies identified traits that are good proxies of species responses across different floras and regions of the world (Díaz et al. 2004; Wright et al. 2004). It is implicit in the use of proxies that there is a loss of information, which may not be a problem when working on broad spatial scales incorporating very contrasting environments subjected to different evolutionary histories. However, the loss of information can be important when applying such general proxies to local species pools, as indicated by the usual high range of values of these global proxies in local communities (Wright et al. 2004). Additionally, many of these global proxies reflect multiple aspects of organisms function, which can show distinct and even opposing responses to environmental drivers. This implies that a set of traits that best explains response to environmental factors in large scales are not always the best under local 
scales. Fashion in the choice of traits might occur when researchers choose traits to be used in a local scale based on large scale comparative studies, without appreciating the real functional significance of these traits in the local species pool and under specific or varying environmental conditions.

To better illustrate this problem, we use as example two widely used plant traits: the leaf mass per area (LMA), and wood density (WD). Importantly, we do not intent to argue against the use of any particular trait, but to demonstrate how the indiscriminate use of a given trait can lead to misinterpretation or lack of predictive power in ecological studies. Wright et al. (2004) described global trade-offs in leaf traits, the so called leaf economic spectrum, as the consequence of contrasting investments of plant species in different structures, resource use and response to environmental factors. These authors indicated LMA, which reflects the leaf construction cost (Witkowski \& Lamont 1991), as a good descriptor of processes occurring from the organism (e.g. how species cope with nutrient availability) to ecosystem-level (e.g. decomposition rates). Importantly, over twenty years ago, Witkowski \& Lamont (1991) have established that the LMA was the product of two components, leaf thickness (TH) and leaf density (DEN), which could vary independently and, in some cases, antagonistically. Even showing similar values of LMA, species response to environmental changes may differ due to differences in DEN and TH (Witkowski \& Lamont 1991; Niinemets 2001). Thus, it is likely that not including TH and DEN may mask the detection of response of plants to environmental conditions and resource availability and, therefore, community assembly.

As pointed out by Hodgson et al. (2011), the popularity of LMA, even masking differential responses of plants along gradients of nutrients and light (Witkowski \& Lamont 1991), is due to historical inertia (Hodgson et al. 2011), since the first studies using LMA as the main descriptor of relative growth rates were carried out in gradients of nutrient availability but not of light (Hodgson et al. 2011). Therefore, it is preferable to use the leaf dry matter content and TH which, unlike the LMA, vary more predictably along environmental gradients (Hodgson et al. 2011).

Traits underlying LMA are better descriptors of ecological processes at different scales. For instance, an inverse relationship between leaf construction cost and leaf longevity was observed in a study of seven species of the genus Piper in different light conditions (Williams et al. 1989). Increases in light availability led to smaller leaf life spans, related to a higher leaf turnover rate despite their having larger leaf construction costs (Williams et al. 1989). In fact, the main trait affecting the longevity is DEN, since a greater proportion of structural tissues could confer greater resistance to the leaves (Ryser 1996). DEN is a better descriptor of response of species to water availability especially in dry environments, while the TH would act primarily in environments where light is the limiting factor (Niinemets 2001). Curiously, in a global analysis, leaf turgor loss point and osmotic pressure were recently shown to be key traits describing drought tolerance between biomes, instead of LMA (Bartlett et al. 2012). Additionally, the importance of traits related to the venation network of leaves, that mediate water and carbon flows in leaves due to routes of distribution of resources, are important underlying traits mediating the relationships between traits in the leaf economic spectrum (Blonder et al. 2010). In this sense, even with similar LMA, species might differ in terms of carbon assimilation, leaf longevity and drought tolerance due to differences in the venation network and leaf turgor loss point (Blonder et al. 2010; Bartlett et al. 2012).

Similarly, wood density (WD) is another "fashionable trait" used to describe processes such as response of plants to water availability (e.g. risks of embolism and hydraulic conductivity), mechanical resistance to disturbance (e.g. wind), and survival rates and carbon stocks at the ecosystem level (Chave et al. 2009). Nonetheless, WD deserves the same care as LMA since it is also the product of several underlying traits related to xylem structures such as vessel diameter, fiber traits, vessel number and lumen fraction (Chave et al. 2009; Zanne et al. 2010). Despite the global negative relationship between WD and risks of mechanical damage and plant mortality (Chave et al. 2009), there is a strong spatial-temporal and taxonomic variation (Kraft et al. 2010), indicating the possible role of other traits behind WD variation. For instance, it has been show that the same strength may be achieved, at lower cost than in high WD species, by low WD species (Larjavaara \& Muller-Landau 2010).

Regarding water relations, a high WD decreases the transport efficiency per sapwood area, promoting more negative values in leaf water potential and scales with cavitation resistance because more negative pressures can occur in the xylem (Meinzer 2003). However, although vessel traits and WD describe two ecological axes related to plant height and soil water content, respectively (Preston et al. 2006), a global analysis revealed that WD explains only $2 \%$ of the variation of plant hydraulic efficiency (Zanne et al. 2010). This is because WD is weakly related to other xylem anatomical traits that better describe water use strategies (Zanne et al. 2010). Even hydraulic failure and tree dieback, which are usually associated with low WD, occurred in high WD species which did not avoid the catastrophic embolism, due to low sensitivity of stomata (Hoffmann et al. 2011). In conclusion, variation in wood density must also be understood based on vessel composition, vessel lumen fraction and non-lumen wood density, which are subject to different selective pressures that affect properties such as hydraulic conductivity and mechanical strength (Zanne et al. 2010).

Not only LMA and WD, but other traits also deserve caution since they are the product of underlying traits that may vary independently, such as leaf water potential, which depends on osmotic pressure and bulk modulus of elasticity (Bhaskar \& Ackerly 2006; Rosado \& de Mattos 2010) and leaf life 
span, dependent on LMA and leaf nitrogen concentration (Wright et al. 2002; Rosado \& de Mattos 2010).

\section{Going Back to Basics: Mechanistic Criteria for Choosing Functional Traits}

As shown above, global patterns of trait variation are not always robust in local communities exposed to environmental change, especially considering that particular traits might be the result of underlying traits that respond to distinct environmental factors. We propose that the choice of traits to predict community and ecosystem response to environmental changes (e.g. climate changes) should be strictly linked to the local environmental drivers and the physiological processes that allow species to cope with conditions and resource availability. This means that, to be able to upscale responses from the individual level to communities and ecosystems, it is necessary to integrate the knowledge of morphology, physiology, life-history, phenology and behavior underlying the traits in a given ecological and evolutionary context. Here, we present a framework with five necessary steps for choosing appropriate traits to produce mechanistic predictions on the response of communities and ecosystems to environmental changes (Figure 1).

1. Identifying environmental drivers: First of all, it is necessary identify the environmental driver of interest (e.g., natural environmental gradient, or predictions for climatic or land-use changes) as well as the time frame that a specified environmental driver will affect the community. For instance, for organisms facing the same conditions along their entire life-time (e.g. fast growing herbaceous vegetation), only at large spatial and temporal scales changes in trait values

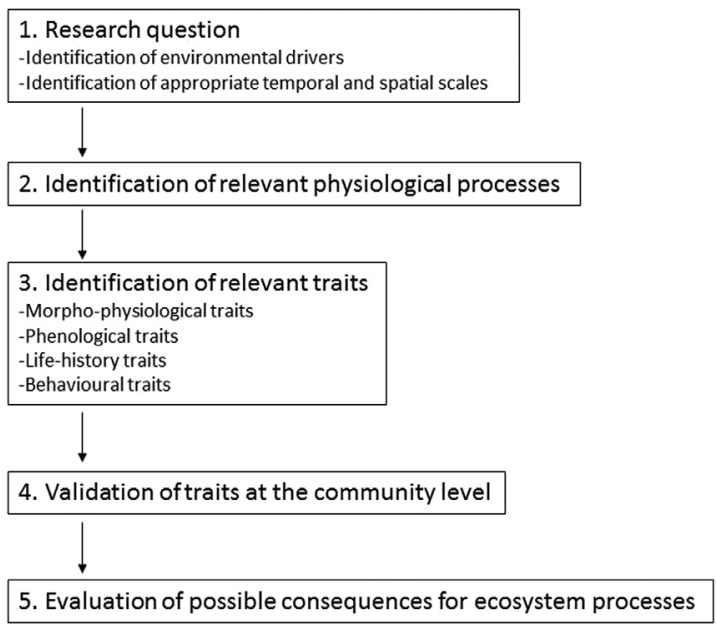

Figure 1. Framework with five necessary steps for choosing appropriate traits to produce mechanistic predictions on the response of communities and ecosystems to environmental changes. are expected due to plasticity (Givnish 2002). Thus, the use of average trait values per species should be sufficient to understand community response. On the other hand, in environments whose species are subjected to major changes in conditions during their lifespan (e.g. slow growing woody vegetation), community dynamics might lag for longer time periods, but it is still possible to use trait plasticity to understand community response (Givnish 2002; Wright \& Sutton-Grier 2012). In this case, intraspecific trait variability should be included.

2. Identifying the relevant physiological processes allowing species to cope with the environmental driver: Physiological processes can be framed in relation to the main ecological forces (e.g. environmental stress, disturbances and interspecific interactions) driving species responses and performance (Keddy 1992; Lambers et al. 2008). Species resistance to unfavorable conditions can be determined by their position along the continuum of physiological avoidance and tolerance strategies. These strategies comprise distinct processes that should be considered when identifying the physiological processes enabling species to withstand the environmental filter (Keddy 1992).

3. Identifying the relevant traits: Traits that affect the selected physiological processes, and therefore species response to the environmental driver, should be selected. In this way, traits to be chosen should vary predictably along environmental gradients (Laughlin et al. 2011). Additionally, chosen traits should also preferably relate to different dimensions of variation (sensu Westoby et al. 2002) describing relevant ecological strategies in a given environment. This means that we must avoid using correlated traits (belonging to the same dimension of variation), which provide redundant information and, in this way, we would maximize the information given by a minimal number of traits. When the chosen trait is the product of other underlying traits it is necessary to investigate if the latter respond independently to the environmental driver of interest. If so, it is essential to use the underlying traits instead of the resultant trait (Witkowski \& Lamont 1991; Rosado \& de Mattos 2010).

4. Validating traits at the community level: It is essential to demonstrate that the selected traits are related to species responses to the environmental driver of interest (Rosado \& de Mattos 2010; Dias et al. $2013 b)$. This validation should be done by means of experimental or observational comparative approach in the ecological context of the study system (Wardle et al. 
1998). This can be done by testing the relationship between trait values and species responses (e.g., shifts in frequency, dominance, and survival) to the environmental driver. As shown above, the assumption that global trade-offs and relationships between traits and environmental factors will hold for local communities might possibly lead to a poor choice of traits.

\section{Evaluating possible consequences for ecosystem} functioning: To evaluate possible consequences to ecosystem processes, two aspects have to be considered. First, we must make a distinction between response traits, those related to species response to a given environmental driver, and effect traits, those related to species effects on a given ecosystem process (Lavorel \& Garnier 2002). Effect traits (e.g., leaf nitrogen content and foliar $\mathrm{pH}$ affecting litter decomposition; Garnier et al. (2004); Cornelissen et al. (2006)) should also be validated by means of observational or experimental comparative studies. If response and effect traits overlap or correlate to each other, directional changes in community composition due to environmental filtering is expected to have strong consequences for ecosystem processes (Suding et al. 2008; Webb et al. 2010). Second, different aspects of community trait composition (i.e., the distribution of trait values of species in a community) can affect ecosystem processes (de Bello et al. 2010; Dias et al. 2013a). Ecosystem processes and properties are mainly determined by the mean effect trait value of the species present in the community, weighted by their relative abundance (the so-called community-weighted mean trait value - CWM; Garnier et al. (2004)). Alternatively, functional diversity (the degree of dissimilarity in trait values between coexisting species - see Villéger et al. (2008)) promotes non-additive effects on ecosystem processes, that is, effects not predictable from singlespecies results due to antagonistic or synergistic interactions among species (Heemsbergen et al. 2004). The prevalence of each of these two aspects on ecosystem functioning is likely to depend on the ecosystem process of interest (Mouillot et al. 2011; Dias et al. 2013a).

\section{Ecophysiological Approaches into Functional Ecology}

We use two studies to exemplify how the use of our conceptual framework can help integrating previous knowledge of species ecophysiology to assist choosing traits to explain distinct ecological processes. Rosado \& de Mattos (2010) investigated patterns of dominance in a coastal sandy plain in Brazil, in which plants are subjected to strong variation on water availability and very low nutrient availability due to the sandy substrate. If woody species dominance rank is associated with their ability to cope with water and nutrient deficiency, this should reflect on species resistance strategies for these stressors. In this study, eighteen functional traits, belonging to distinct dimensions of variation (Westoby et al. 2002) describing growth, drought tolerance and nutrient-use efficiency were used to explain species dominance ranking. Among morphological (e.g. LMA, TH, leaf succulence and WD), physiological (leaf water potential, bulk modulus of elasticity, osmotic pressure and leaf nitrogen isotope) and phenological traits (leaf turnover rate, leaf longevity and leaf death rate), the species dominance was described by the positively association with higher leaf water potential, bulk modulus of elasticity and more negative nitrogen isotopic composition, related to a high conservative resource use (Rosado \& de Mattos 2010). These associations with species dominance validated those traits as good proxies for understanding species assemblage on this environment. On the other hand, the two co-dominant species, Clusia hilariana and Protium icicariba, showed high divergence in LMA (321.7 and $121.6 \mathrm{gm}^{-2}$, respectively), which is related to species effect on litter decomposition (Dias 2008). This finding reveals the importance of the choice of traits based on an ecophysiological knowledge especially when fashionable traits (e.g. LMA and WD) were unable to elucidate patterns of community structure and species dominance; as in the case for this resource-poor environment.

Although the functional approach has been developed mostly under the scope of plant ecology, recent studies have successfully used functional traits to explain response of animal communities to environmental factors (Blaum et al. 2011; Dias et al. 2013b). However, as there is still no consensus among animal ecologists on what the most important traits are and what is the best way to measure them, establishing criteria for choosing and validating adequate traits is especially important in the scope of animal ecology. Dias et al. (2013b) showed a similar rationale as the one formalized in our framework (Figure 1) for choosing traits explaining terrestrial isopod species distribution along gradients of soil moisture. They selected desiccation resistance as a potential good descriptor of species response to water availability. Taking into account that the physiological ability of an organism to show resistance to unfavourable conditions can be determined by physiological avoidance and tolerance strategies, Dias et al. (2013b) showed that water loss rate (avoidance) and fatal water loss (tolerance) explained $90 \%$ of interspecific variation in desiccation resistance, with water loss rate being the main mechanism determining species desiccation resistance. They also showed that body size could be a surrogate for desiccation resistance due to its effect on water loss rate. The positive relationship of water loss rate and negative relationship of body size with species frequency along increasing soil moisture levels validated these traits as good proxies for understanding isopod community responses to changes in 
water availability. This study illustrates the importance of solid ecophysiological knowledge and the implementation of validation procedures when identifying and quantifying the functional traits for prediction of species and community' responses to environmental changes.

\section{Conclusions}

Our motivation for elaborating this article is the perception that the functional ecologists have overlooked the importance of ecophysiology and the importance of seeking general principles or criteria when choosing traits for understanding processes at the community and ecosystem levels. The careful choice of traits gains importance especially when: (i) functional ecology has been used as an important tool for conservation purposes (Wikelski \& Cooke 2006; de Bello et al. 2010; Drenovsky et al. 2012); (ii) the intraspecific variation is "coming back" to community ecology (Violle et al. 2012) and the easiness of measuring fashionable traits for all individuals in a community, without identify the relevant physiological processes, may not appropriately describe response of species, community assembly and ecosystem functioning.

Although a minimum list of traits might be enough to answer a given ecological question (Sonnier et al. 2012), which traits are necessary is the key question. Therefore, a deep ecophysiological understanding is essential to identify more responsive traits to a given environmental driver (Rosado \& de Mattos 2010; Bartlett et al. 2012; Dias et al. 2013b). Studies on community assembly and ecosystem functioning are often using ecophysiological traits as descriptors, but hot topics (e.g. functional diversity) should not outweigh important aspects of scientific activity; which are the rigor and critical analysis of the concepts and tools used. Our framework provides the criteria for choosing traits based on well-defined mechanisms when up-scaling responses of individuals to communities and ecosystems.

\section{Acknowledgments}

We thank all the members of the Laboratório de Ecologia Vegetal (UFRJ) for all good discussions in the last years, Tim Moulton who carefully read and comment on the manuscript and two anonymous reviewers for critiques and suggestions. Bruno H.P. Rosado thanks Profs. Glauco Machado and Paulo Inácio, from the University of São Paulo, for the invitation to participate in the Field Course "Ecology of the Atlantic Rain Forest", what motivated the initial writing of this manuscript. André T.C. Dias was financed by NWO postdoctoral grant number NWO / 819.01.017. Eduardo A. de Mattos thanks financial support from $\mathrm{CNPq}$ and FAPERJ.

\section{References}

Bartlett MK, Scoffoni C \& Sack L, 2012. The determinants of leaf turgor loss point and prediction of drought tolerance of species and biomes: a global meta-analysis. Ecology
Letters, 15:393-405. PMid:22435987. http://dx.doi. org/10.1111/j.1461-0248.2012.01751.x

Beyschlag W \& Ryel RJ, 2007. Plant physiological ecology: An essential link for integrating across disciplines and scales in plant ecology. Flora, 202:608-623. http://dx.doi. org/10.1016/j.flora.2007.05.001

Bhaskar R \& Ackerly D, 2006. Ecological relevance of minimum seasonal water potential. Physiologia Plantarum, 127:353-359. http://dx.doi.org/10.1111/j.1399-3054.2006.00718.x

Blaum $\mathrm{N}$ et al., 2011. How functional is functional? Ecological groupings in terrestrial animal ecology: towards an animal functional type approach. Biodiversity and Conservation, 20: 2333-2345. http://dx.doi.org/10.1007/s10531-011-9995-1

Blonder B et al., 2010. Venation networks and the origin of the leaf economics spectrum. Ecology Letters, 14:91-100. PMid:21073643. http://dx.doi. org/10.1111/j.1461-0248.2010.01554.x

Borchert R, 1994. Soil and stem water storage determine phenology and distribution of tropical dry forests trees. Ecology, 75:1437-1449. http://dx.doi.org/10.2307/1937467

Chave J et al., 2009. Towards a worldwide wood economics spectrum. Ecology Letters, 12:351-366. PMid:19243406. http://dx.doi.org/10.1111/j.1461-0248.2009.01285.x

Cornelissen JHC et al., 1999. Leaf structure and defense control litter decomposition rate across species and life forms in regional floras on two continents. New Phytologist, 143:191200. http://dx.doi.org/10.1046/j.1469-8137.1999.00430.x

Cornelissen JHC et al., 2003. A handbook of protocols for standardised and easy measurement of plant functional traits worldwide. Australian Journal of Botany, 51:335-380. http://dx.doi.org/10.1071/BT02124

Cornelissen JHC et al., 2006. Foliar pH as a new plant trait: can it explain variation in foliar chemistry and carbon cycling processes among subarctic plant species and types? Oecologia, 147:315-326. PMid:16217678. http://dx.doi org/10.1007/s00442-005-0269-Z

de Bello F et al., 2010. Towards an assessment of multiple ecosystem processes and services via functional traits. Biodiversity and Conservation, 19:2873-2893. http://dx.doi. org/10.1007/s10531-010-9850-9

Dias ATC, 2008. O papel das espécies da restinga aberta arbustiva de Clusia no funcionamento do ecossistema. [Tese]. Rio de Janeiro: Universidade Federal do Rio de Janeiro.

Dias ATC et al., 2013a. An experimental framework to identify community functional components driving ecosystem processes and services delivery. Journal of Ecology, 101:29-37. http://dx.doi.org/10.1111/1365-2745.12024

Dias ATC et al., 2013b. Traits underpinning desiccation resistance explain distribution patterns of terrestrial isopods. Oecologia, 172:667-77. http://dx.doi.org/10.1007/s00442-012-2541-3

Díaz S et al., 2002. Does hairiness matter in Harare? Resolving controversy in global comparisons of plant trait responses to ecosystem disturbance. New Phytologist, 154:7-9. http:// dx.doi.org/10.1046/j.1469-8137.2002.00362.x 
Díaz S et al., 2004. The plant traits that drive ecosystems: Evidence from three continents. Journal of Vegetation Science, 15:295-304.

Drenovsky RE et al., 2012: A functional trait perspective on plant invasion. Annals of Botany, 110:141-153. PMid:22589328. http://dx.doi.org/10.1093/aob/mcs100

Fauset $S$ et al., 2012: Drought-induced shifts in the floristic and functional composition of tropical forests in Ghana. Ecology Letters, 15:1120-1129. PMid:22812661. http:// dx.doi.org/10.1111/j.1461-0248.2012.01834.x

Garnier E et al., 2004. Plant functional markers capture ecosystem properties during secondary succession. Ecology, 85:2630-2637. http://dx.doi.org/10.1890/03-0799

Givnish TJ, 2002. Ecological constraints on the evolution of plasticity in plants. Evolutionary Ecology, 16:213-242. http:// dx.doi.org/10.1023/A:1019676410041

Grime JP, 1977. Evidence for the existence of three primary strategies in plants and its relevance to ecological and evolutionary theory. The American Naturalist, 111:169-194. http://dx.doi.org/10.1086/283244

Heemsbergen DA et al., 2004. Biodiversity effects on soil processes explained by interspecific functional dissimilarity. Science, 306:1019-1020. PMid:15528441. http://dx.doi. org/10.1126/science.1101865

Hodgson JG et al., 2011. Is leaf dry matter content a better predictor of soil fertility than specific leaf area?. Annals of Botany, 108:1337-1345. PMid:21948627 PMCid:3197453. http://dx.doi.org/10.1093/aob/mcr225

Hoffmann WA et al., 2011. Hydraulic failure and tree dieback are associated with high wood density in a temperate forest under extreme drought. Global Change Biology, 17:27312742. http://dx.doi.org/10.1111/j.1365-2486.2011.02401.x

Keddy PA, 1992. Assembly and response rules: two goals for predictive community ecology. Journal of Vegetation Science, 3:157-164. http://dx.doi.org/10.2307/3235676

Kraft NJB et al., 2010. The relationship between wood density and mortality in a global tropical forest data set. New Phytologist, 188:1124-1136. PMid:21058950. http://dx.doi. org/10.1111/j.1469-8137.2010.03444.x

Lambers H, Chapin III FS \& Pons TL, 2008. Plant Physiological Ecology. Springer. http://dx.doi. org/10.1007/978-0-387-78341-3

Larjavaara M \& Muller-Landau HC, 2010. Rethinking the value of high wood density. Functional Ecology, 24:701-705. http:// dx.doi.org/10.1111/j.1365-2435.2010.01698.x

Laughlin DC et al., 2011. Climatic constraints on trait-based forest assembly. Journal of Ecology, 1489-1499. http://dx.doi. org/10.1111/j.1365-2745.2011.01885.x

Lavorel S \& Garnier E, 2002. Predicting changes in community composition and ecosystem functioning from plants traits: revisiting the Holy Grail. Functional Ecology, 16:545-556. http://dx.doi.org/10.1046/j.1365-2435.2002.00664.x

Lavorel S et al., 2008. Assessing functional diversity in the field - methodology matters! Functional Ecology, 22:134-147.
Markesteijn L et al., 2011. Ecological differentiation in xylem cavitation resistance is associated with stem and leaf structural traits. Plant, Cell \& Environment, 34:137-148. PMid:20946587. http://dx.doi.org/10.1111/j.1365-3040.2010.02231.x

Meinzer F, 2003. Functional Convergence in plant responses to the environment. Oecologia, 134:1-11. PMid:12647172. http://dx.doi.org/10.1007/s00442-002-1088-0

Mouillot D et al., 2011. Functional structure of biological communities predicts ecosystem multifunctionality. PLoS ONE, 6:17476. PMid:21423747 PMCid:3053366. http:// dx.doi.org/10.1371/journal.pone.0017476

Niinemets U, 2001. Global-scale climatic controls of leaf dry mass per area density, and thickness in trees and shrubs. Ecology, 82:453-469. http://dx.doi. org/10.1890/0012-9658(2001)082[0453:GSCCOL]2.0.CO;2

Preston K, Cornwell WK \& Denoyer JL, 2006. Wood density and vessel traits as distinct correlates of ecological strategy in 51 California coast range angiosperms. New Phytologist, 170:807-818. PMid:16684240. http://dx.doi. org/10.1111/j.1469-8137.2006.01712.x

Reich PB, Walters MB \& Ellsworth DS, 1992. Leaf life-span in relation to leaf, plant, and stand characteristics among diverse ecosystems. Ecological Monographs, 62:365-392. http://dx.doi.org/10.2307/2937116

Rosado BHP \& de Mattos EA, 2010. Interspecific variation of functional traits in a CAM-tree dominated sandy coastal plain. Journal of Vegetation Science, 21:43-54. http://dx.doi. org/10.1111/j.1654-1103.2009.01119.x

Ryser P, 1996. The importance of tissue density for growth and life span of leaves and roots: a comparison of five ecologically contrasting grasses. Functional Ecology, 10:717-723. http:// dx.doi.org/10.2307/2390506

Shipley B, Vile D \& Garnier E, 2006. From Plant Traits to Plant Communities: A Statistical Mechanistic Approach to Biodiversity. Science, 314:812-814. PMid:17023613. http:// dx.doi.org/10.1126/science.1131344

Sonnier G et al., 2012. Quantifying trait selection driving community assembly: a test in herbaceous plant communities under contrasted land use regimes. Oikos, 121:1103-1111. http://dx.doi.org/10.1111/j.1600-0706.2011.19871.x

Suding KN et al., 2008. Scaling environmental change through the community-level: a trait-based response-and-effect framework for plants. Global Change Biology, 14:1125-1140. http://dx.doi.org/10.1111/j.1365-2486.2008.01557.x

Villéger S, Mason NWH \& Mouillot D, 2008. New multidimensional functional diversity indices for a multifaceted framework in functional ecology. Ecology, 89:2290-2301. PMid:18724739. http://dx.doi. org/10.1890/07-1206.1

Violle C et al., 2012. The return of the variance: intraspecific variability in community ecology. Trends in Ecology \& Evolution, 27:244-252. PMid:22244797. http://dx.doi. org/10.1016/j.tree.2011.11.014

Wardle DA et al., 1998. Can comparative approaches based on plant ecophysiological traits predict the nature of biotic interactions and individual plant species effects in 
ecosystems? Journal of Ecology, 86:405-420. http://dx.doi. org/10.1046/j.1365-2745.1998.00268.x

Webb CT et al., 2010. A structured and dynamic framework to advance traits-based theory and prediction in ecology. Ecology Letters, 13:267-283. PMid:20455917. http://dx.doi. org/10.1111/j.1461-0248.2010.01444.x

Weiher E et al., 1999. Challenging Theophrastus: A common core list of plant traits for functional ecology. Journal of Vegetation Science, 10:609-620. http://dx.doi.org/10.2307/3237076

Westoby M et al., 2002. Plant ecological strategies: some leading dimensions of variation between species. Annual Review of Ecology, Evolution, and Systematics, 33:125-159. http:// dx.doi.org/10.1146/annurev.ecolsys.33.010802.150452

Wikelski M \& Cooke SJ, 2006. Conservation Physiology. Trends in Ecology \& Evolution, 21:38-46. PMid:16701468. http:// dx.doi.org/10.1016/j.tree.2005.10.018

Williams K, Field CB \& Mooney HA, 1989. Relationships among leaf construction cost, leaf longevity, and light environment in rain-forest plants of the genus Piper. The American Naturalist, 133:198-211. http://dx.doi.org/10.1086/284910

Witkowski ETF \& Lamont BB, 1991. Leaf specific mass confounds leaf density and thickness. Oecologia, 88:486-493.

Wright IJ, Westoby M \& Reich PB, 2002. Convergence towards higher leaf mass per area in dry and nutrient-poor has different consequences for leaf life span. Journal of Ecology, 90:534453. http://dx.doi.org/10.1046/j.1365-2745.2002.00689.x

Wright IJ et al., 2004. The world wide leaf economics spectrum. Nature, 428:821-827. PMid:15103368. http://dx.doi. org/10.1038/nature02403

Wright JP \& Sutton-Grier A, 2012. Does the leaf economic spectrum hold within local species pools across varying environmental conditions? Functional Ecology, 26:1390-1398. http://dx.doi.org/10.1111/1365-2435.12001

Zanne AE et al., 2010. Angiosperm wood structure: global patterns in vessel anatomy and their relation to wood density and potential conductivity. American Journal of Botany, 97:207-215. http://dx.doi.org/10.3732/ajb.0900178

Received: April 2013

First decision: May 2013

Accepted: June 2013 